\title{
Research on Risk Pre-warning Evaluation System of Enterprise Financing Based on Big Data Processing Siyun Xu, Qingshan Tong
}

\author{
Hebei Finance University, Baoding, Hebei, 071051, China \\ Science and Technology Financial Key Laboratory of Hebei Province, Baoding, Hebei, 071051, \\ China \\ Hebei Finance University, Baoding, Hebei, 071051, China
}

\begin{abstract}
Keywords: small and medium-sized technology-based enterprises, financing, pre-warning system, countermeasures.
\end{abstract}

\begin{abstract}
Small and medium-sized technological enterprises in Hebei Province are featuring in great innovation, high increase; large cost, high risk and high profits, and difficulty of financing as well as great risks bring obstacles for those private enterprises to industrialize their high-tech products. Thus, the enterprises cannot be truly developed and their economic potential cannot be fully tapped. This paper, against this backdrop, adopts the combination of qualitative analysis and quantitative analysis to make evaluation upon financing risks and builds up a risk pre-warning evaluation systems of corporate financing. Based on analytical hierarchy process, this paper evaluates the influences of this system on financing risks to verify the theoretical researches in this paper and provide reference for financing risk management in private technical small and medium-sized enterprises.
\end{abstract}

\section{Introduction}

Gradual building-up and improvement of socialist market economy system and large-scale reform of state-owned enterprises enable small and medium-sized enterprises to achieve great development. [1,2,3] However, the situation for living is not optimistic. According to a report issued by China Democratic National Construction Association, at present, the average life expectancy of China's small and medium-sized enterprises is only 3.7 years, quite temporary compared with their counterparts in other countries The main reason why those enterprises are so fragile is that, in addition to limitations of environment and operation, there is a big challenge related to financing difficulty.

At present, most scholars focus on how to inject investment into those technological medium and small size enterprises for greater and faster development such as financing channels, which makes the high-risk and great volatility concealed by "as long as we have money”. Other scholars mainly study financial crisis pre-warning indexes for listed companies. This paper, on the basis of features of technical small and medium-sized enterprises in Hebei Province, sets up a pre-warning system of financial risks so as to evaluate the risk level and conduct targeted countermeasures.

\section{Analysis of Financing Situation of Small and medium-sized Enterprises in Hebei Province}

\subsection{Current Financing Stae and Exsisting Problem}

Small and medium-sized enterprises in Hebei Province are in face of liquidity squeeze and short supply of operating funds. As the decrease profits of small and medium-sized enterprises, the difficulty in financing has become a hot topic and researches and solutions are on the top of the agenda. Private borrowing is relatively frequent among Hebei small and medium-sized enterprises. According to the research, there are 26.6\% (79) enterprises have records of loaning. However, this loaning interest shows a trend of usury as shown in Figure 1, which should be strictly contained by the government. Therefore, the capital cost is always higher then expected profits related to maintaining and expanding production, which will lead to greater risk of interests. 


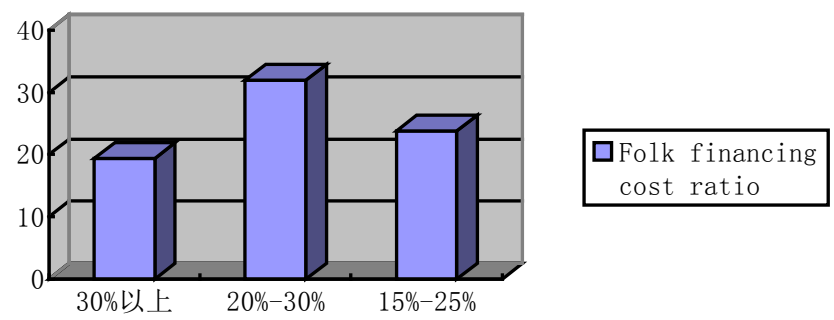

Fig.1:Range of Folk Financing Interest

Small and medium-sized enterprises, in order to maintain operation or gain money, have to change normal financing channels and begin folk financing. Influenced by market interest and supply-demand relationship of capitals, the interest of folk financing is greatly soaring. Thus, the enterprises are in face of severe challenges of rapid increase of financing capitals. Figuer 2 shows seasonal increase of folk financing interest in Langfang. Several small and medium-sized enterprises are closed or bankrupted due to financing lacking and financing chain breaking.

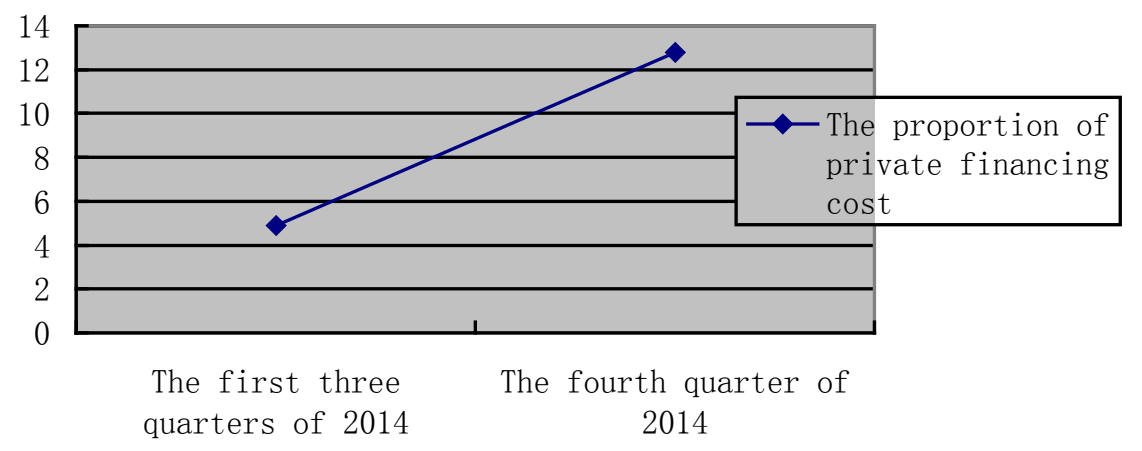

Fig.2: Trend of Interest of Langfang Fold Financing

Against the backdrop of China's great support of small and medium-sized enterprises, those companies achieve great opportunities to enter the capital market. However, as the society does not totally change the traditional idea, there are some difficulties for capital market actions such as list application in normal process, indirect listed by shares transger or issue enterprise debt in bond market. Figure 3 shows some reasons throught analysis. Influenced by national policies and banking guideline, small and medium-sized enterprises tend to be hard to get loan from banks. Thus, indirect financing channels are blocked. And the direct financing also has a problem. Therefore, the enterprises have relatively weak financing ability from other channels and the channel is quite simple. We need to pay more attention to financing in small and medium-sized enterprises, adjust governmental policies and optimize financing environemnt for those enterprises so as to provide more space for development.

\subsection{Existing Problems in Small and medium-sized Enterprises in Hebei Province}

First of all, small and medium-sized enterprise financing does not rely on official channels, thus the cost is relatively high. Cases show that the financing channel of those enterprises is mainly self-raised. As there arelimitations of loan in state-owned banks and other commercial banks and severe conditions for application, small and medium-sized enterprises would rahter choose folk financing to change deficit than get money from official channels. Financing party usually borrows capitals from black market with costs much higher than legal one, which is against the law. And great credit risk is coming. In addition, small and medium-sized enterprises, at present, are not completely equipped with direct financing capability of using share market and bond market. As the social idea is not totally changed, there are still difficulties for small and medium-sized enterprises to conduct capital market actions such as direct listed, indirect listed by share transfer or issuing enterprise debt in the bond market. Here are the conclusions through analysisi as shown in Figure 3. 


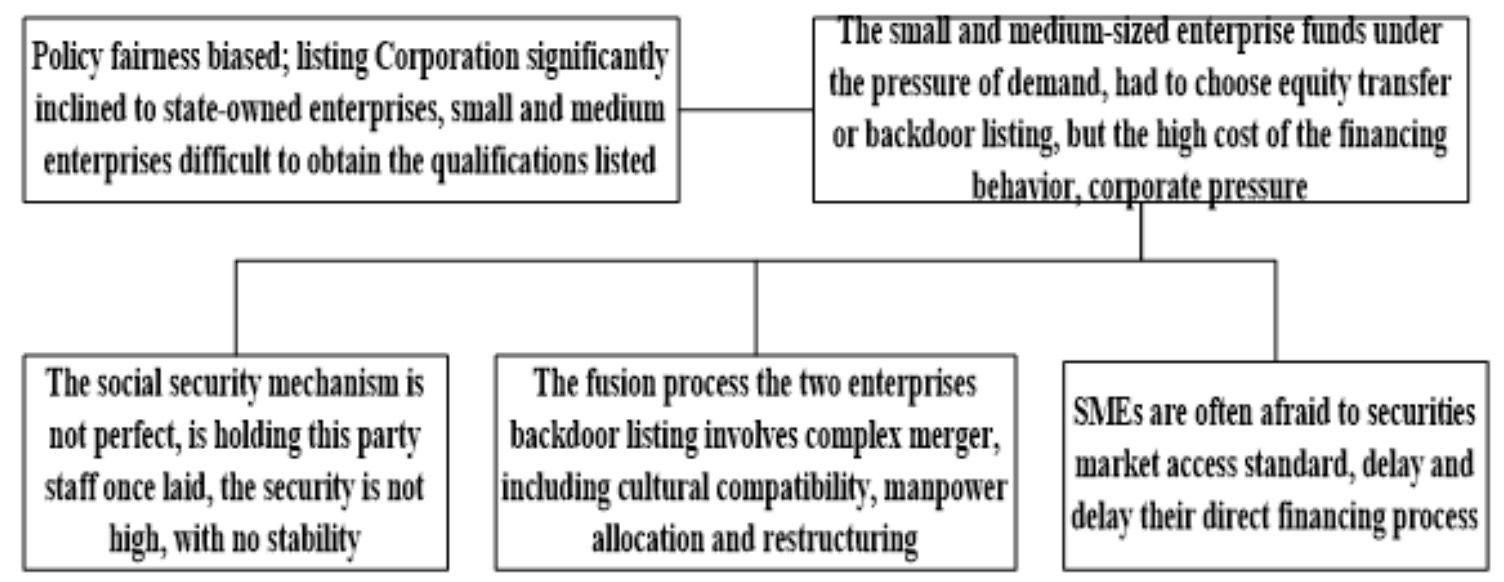

Fig.3: Various Capital Market Actions of Small and medium-sized Enterprises

\section{Risk Pre-warning Indicator System Building of Technological Small and medium-sized Enterprise Financing}

\subsection{Building of the Indicator System}

The pre-warning indicators of financing risks and analysis of those indicators, we can see those indicators are matched to corresponding financing risks. The indicators cover all factors that could bring financing risks to small and medium-sized techonology-based enterprises, as shown in Figure 4.

Nevertheless, not all the enterprises are the same as they have different features and development stages. Therefore, small and medium-sized enterprises, when referring to financing risk pre-warning indicators, should adopt suitable indicators according to individual situation. Meanwhile, enterprises should make different adjustment according to pre-warning results, actual situation and individual index weight so as to make more accurate, effective and feasible financing risk pre-warning.

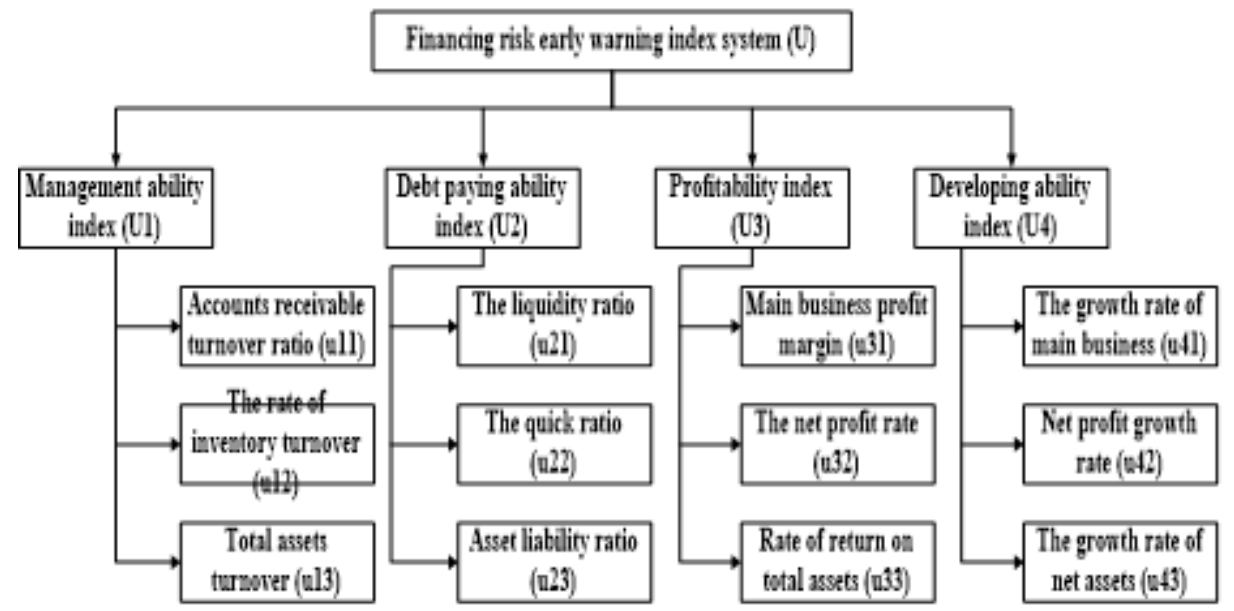

Fig.4: Risk Pre-warning Indicator System of Technological Small and medium-sized Enterprise

Financing

\subsection{Confirmation of Financing Risk Index Weight}

Index weight is the reflection of medium or lower index to upper index in the system. The confirmation of the index weight is an important part of the financing risk pre-warning system, exerting great influence on the accuracy of pre-warning. This paper, adopting analytic hierarchy process, sets up paired comparison to confirm the index weight of all the indicators.

We assume the general target is A, first-class indicators are A1, A2, A3, second-class indicators are A21, A22, A23 under A2, A31, A32, A33 under A3, the structure model can be 
set up as follow:

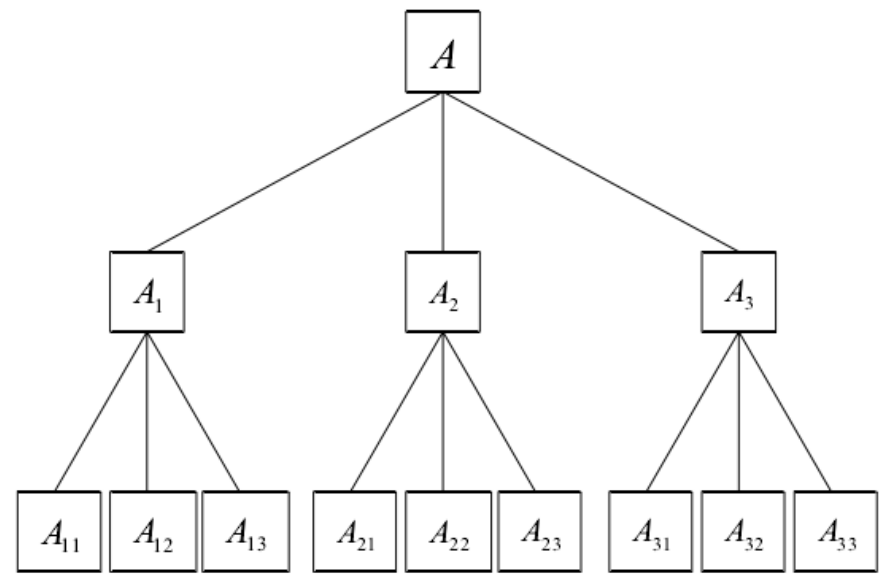

Fig.5: Hierarchical Structure Model

The paired comparison matrix mainly shows the influence of indicators at lower level on counterparts at higher level, makes a comparison between two different levels and confirms the weight to construct matrix and calculates indicator weight of indicators on next level. The sum of index weight is 1 . Matrix calculation can give the result of the eigenvalue of matrix A and uniform corresponding eigenvalue to get index weight.

\subsection{Confirmation of Financing Risk Pre-warning Indicator Evaluation Results}

The dimensionless method of the pre-warning indicators transfer indicators into the same unit of measurement at the same level and eradicate influences as well as evaluation value of original index information. In order to meeting demands of model calculation, we need to reserve the number between 0 and 1.

We assume the taking value interval is $\left[F_{i j}^{1}, F_{i j}^{2}\right] . F_{i j}^{1}$ is the risk critical value of indicator uij and $F_{i j}^{2}$ is the suitable value of indicator uij. The values at different levels change into different directions and the subordinating degree functions of uij are also different.

i) When values at lower and higher levels change in the same direction, the subordinating degree function of uij is:

$$
u_{i j}= \begin{cases}0 & \mathrm{u}_{\mathrm{ij}} \leq F_{i j}^{1} \\ \frac{u_{i j}-F_{i j}^{1}}{F_{i j}^{2}-F_{i j}^{1}} & \mathrm{~F}_{\mathrm{ij}}^{1} \leq u_{i j} \leq F_{i j}^{2} \\ 1 & \mathrm{u}_{\mathrm{ij}} \geq F_{i j}^{2}\end{cases}
$$

ii) When values at lower and higher levels change in different directions, the subordinating degree function of uij is:

$$
u_{i j}= \begin{cases}0 & \mathrm{u}_{\mathrm{ij}} \leq F_{i j}^{2} \\ \frac{F_{i j}^{1}-u_{i j}}{F_{i j}^{1}-F_{i j}^{2}} & \mathrm{~F}_{\mathrm{ij}}^{2} \leq u_{i j} \leq F_{i j}^{1} \\ 1 & \mathrm{u}_{\mathrm{ij}} \geq F_{i j}^{1}\end{cases}
$$

The dimensionless method uij is multiple by individual index weight wij and then added to get evaluation of estimate at first-class Ui, then multiple and add Ui and Wi to get the final evaluation result of the financing risk pre-warning indicator system. Name the example of the hierarchical structure model, the result can be shown in the following formula: 


$$
\begin{aligned}
& U_{1}=\sum_{i=1}^{3} \omega_{1 i} u_{1 i} \\
& U_{2}=\sum_{i=1}^{3} \omega_{2 i} u_{2 i} \\
& U_{3}=\sum_{i=1}^{3} \omega_{3 i} u_{3 i}
\end{aligned}
$$

\subsection{Confirmation of Financing Risk}

The scale of risk refers to the damage caused by the risk. Here, this paper divides risk into five levels as excellent, normal, low, medium and high, represented by V1, V2, V3, V4, V5. Based on previous results of financing risk pre-waming indicator evaluation, there are five ranges of the financing risk levels, represented by $\mathrm{V} 1 \in(0.8,1], \mathrm{V} 2 \in(0.6,0.8], \mathrm{V} 3 \in(0.4,0.6]$, $\mathrm{V} 1 \in(0.2,0.4]$. Those enterprises should make different pre-warning signals according to different evaluation results, provide reference to decision-makers, take effective measures to prevent financing risks so as to enhance the ability of resisting financing risks.

\section{Empirical Study of Small and medium-sized Technology-based Enterprise}

The sample data of this paper comes from a mature small and medium-sized electronic limited liability company in Tangshan City, Hebei Province. For 7 years in a row since 1997, it has been one of the top 100 electronic component enterprises. This enterprise is also rewarded by Ministry of Science and Technology as Technical Innovation Model Enterprise, one of the Significant Export Enterprises with Technology by the Science Ministry and Commercial Ministry, Supporting Enterprise of National Mobile Phone by the Ministry of Information Industry and High-tech Enterprise by Science and Technology Agency in Hebei Proince. The company, sticking to management and technical innovation, has become a large corporate of piezoelectric quartz and made remarkable social and economic profits.

The paper shows financial indicators that are necessary for the evaluation system and calculates single effect coefficient on the basis of mentioned theory. The results are shown in Table 1.

Table 1 Single Effect Coefficient of Various Indicators

\begin{tabular}{|c|c|c|}
\hline First-class Indicator & Second-class Indicator & Single Effect Coefficient \\
\hline Capital Repaying Ability & Net Profit Margin & $(0.038 / 0.0909) \times 40+60=76.89$ \\
\cline { 2 - 3 } & Return on Equity & $(0.06 / 0.0748) \times 40+60=92.09$ \\
\cline { 2 - 3 } $\begin{array}{c}\text { Capital Utilization } \\
\text { Ability }\end{array}$ & Liquidity Ratio & $(0.26 / 1.0507) \times 40+60=69.90$ \\
\cline { 2 - 3 } & Interest Multiple & $(11.21 / 39.2269) \times 40+60=71.43$ \\
\hline \multirow{3}{*}{$\begin{array}{c}\text { Ratio of Cash } \\
\text { Circulating Liabilities }\end{array}$} & $0.255 / 0.06) \times 40+60=-100$ \\
\cline { 2 - 3 } & Asset-liability Ratio & $(0.2248 / 0.3802) \times 40+60=83.65$ \\
\hline & $\begin{array}{c}\text { Inventory Turnover } \\
\text { Rate }\end{array}$ & $12.955 / 17.125) \times 40+60=29.74$ \\
\cline { 2 - 3 } & Capitalization Rate & $0.06 / 0.3) \times 40+60=52$ \\
\cline { 2 - 3 } & Capital Immobilization & 100 \\
& Rate & \\
\hline
\end{tabular}

Comprehensive Effect Coefficient $=\sum$ (Single Effect Coefficient $\times$ Index Weight of the Indicator )/ Index Weight

$=0.6 \times 0.24 \times 76.89+0.6 \times 0.36 \times 92.09+0.6 \times 0.1 \times 69.90+0.6 \times 0.15 \times 71.43-0.6 \times 0.15 \times 110+0.25 \times 0.375 \times$ $100+0.25 \times 0.375 \times 100+0.25 \times 0.25 \times 29.74+0.15 \times 0.4 \times 83.65+0.15 \times 0.2 \times 52+0.15 \times 0.2 \times 100+0.15 \times 0.2 \times 1$ $00=64.88$. 
The comprehensive effect coefficient is 64.88. According to the critical standard of enterprises financing risk status, $60<66.88<70$, we can know that Hengxing Technology Company is in face of high risk. The financing demands cannot be met and the condition of assets is relatively worse. This conclusion is in line with the actual situation.

\section{Countermeasures against Financing Risk Prevention and Control of Private Small and medium-sized Technology-based Enterprises}

Small and medium-sized technology-based enterprises should take countermeasures against risk prevention and control, while financing channels must be guaranteed. Thus, relevant departments in the government should create a relatively ease financing environment for those enterprises. Featuring in small scale, low capability, high risk, unimproved system and great financing demands, the enterprises should also improve themselves inside to effectively prevent and control financing risks.

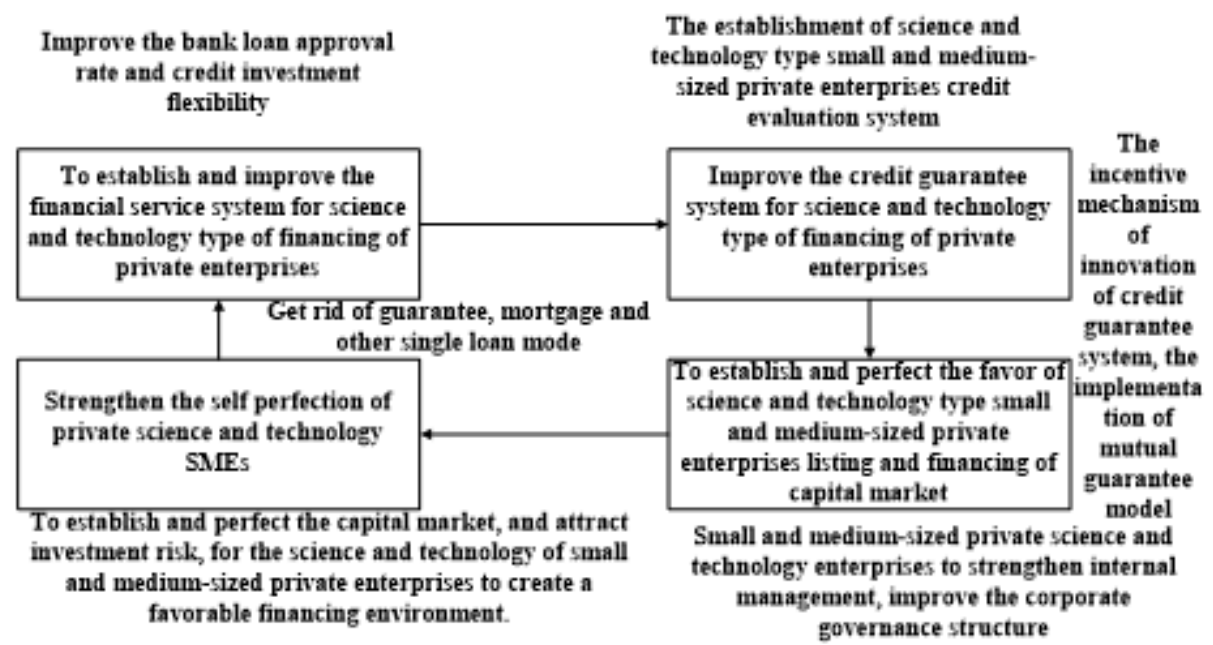

Fig.6: Prevention and Control Countermeasures against Risks

We need to build up and improve the financing service system which is beneficial for the financing process of private small and medium-sized enterprises financing, improve flexibility of banking loan approval and loan input, simplify loan process, enhance capital allocation, expand financing service and improve service programs. What's more, those enterprises should get rid of single loan mode related to guarantee or mortgage and adopt multiple credit vehicles. The government should provide financing support for interest rate liberalization, decrease loan cost by adjusting interest and promote initiative of commercial banks to loan to small and medium-sized enterprises.

We need to set up credit evaluation system for small and medium-sized technology-based enterprises, make innovation for stimulation system of credit guarantee system, implement mutual guarantee mode and set up multi-level risk compensation system and separation system. Risk investment is one of the most important channels of financing for small and medium-sized enterprises during the early stage, thus great development in risk investment is significant for small and medium-sized enterprise financing. The enterprises should strengthen internal management and improve the company structure. They also need to improve financing and audit system and optimize financing structure. Improved financing and audit system can effectively protect the knowing right of investors, which enables investors to know the operational status of the company in time. Thus, the unmatched information will be decreased between investors and enterprises so as to attract capitals to the maximum.

\section{Conclusions}

On the basis of risk identification and evaluation, this paper analyzes prevention and control 
countermeasures against financing risks of private small and medium sized enterprises, proposes specific methods such as financing risk averse, deflection, separation, control and retention, explains the content of measures including setting up and improving financial service system, improve credit guarantee system, setting up and enhancing capital market as well as strengthen self-improvement within enterprises. All of those can provide effective reference for preventing and controlling financing risks.

\section{Acknowledgements}

The research work was supported by Science and Technology Financial Key Laboratory of Hebei Province under Grant No. HBTFKL201417 and Hebei Education Department under Grant No. SD141038.

\section{References}

[1] Chen Yuhui. Risk management: philosophy to test enterprises[J]. Chemical Engineering,2010(09):8-10

[2] Guo Bin, Dai Xiaomin. China risk pre-warning model research: basedon financial and non-financila factors [J].Finance Research,2006(2)

[3] Guo Weigang, Zhao Lijuan. Research on enterprise consistent capbility evaluation and risk pre-warning, based on manufacture enterprises in Zhejiang Province [J].Finance and Economics Magzine,2011(3):110-116

[4] Hu Miaohong. Research on evaluation indicator system of financial risks in private enterprises [J]. Modern Economy (Middle Periodical),2010,9(1):76-77

[5] Zhang Minghua. Research on financing risk pre-warining system of small and medium-sized enterprises [D]. Master's Thesis of Capital University of Economics and Business.2006,3. 6-7.

[6] Wang Jianmin. Analysis of building up multiple small and medium-sized enterprise financing mode [J] .Inner Mongolia Finance Research，2012（9）。

[7] Kan Jingyang. Analysis of financing channel expansion of small and medium-sized technology-based enterprises [J] .Financial Teaching and Researching, 2012 (6)

[8] Ma Zhonghua, Xia Jiqiang. Analysis of financial pre-warning method [ $\mathrm{J}$ ].Accountant Friend, 2012 (3).

[9] Wu Yingyu. Research on enterprise financial difficulty based on the theory of constraints [J]. Modern Economy Discussion.2010,2.27-29..

[10] Zheng Caifei. Application of scoring model in financing risk testing and crisis pre-warning in private listed companiyes in Zhejiang Province [J] Commercial Economy. 2011,11: 104-106. 